\title{
Film Subtitles and Listening Comprehension Ability of Intermediate EFL Learners
}

\author{
Amin Saed ${ }^{1}$, Arash Yazdani ${ }^{1}$, Mohsen Askary ${ }^{2}$ \\ ${ }^{1}$ English Department, Faculty of Management and Humanities, Chabahar Maritime University, Chabahar, Iran \\ ${ }^{2}$ English Department, Ferdowsi University, Faculty of Letters and Humanities, Mashhad, Iran
}

Email address:

Amin.saed@cmu.ac.ir(A. Saed),Arash678@gmail.com (A. Yazdani), Mohsen_Askary71@yahoo.com (M. Askary)

To cite this article:

Amin Saed, Arash Yazdani, Mohsen Askary. Film Subtitles and Listening Comprehension Ability of Intermediate EFL Learners. International Journal of Applied Linguistics and Translation. Vol. 2, No. 3, 2016, pp. 29-32. doi: 10.11648/j.ijalt.20160203.12

Received: April 22, 2016; Accepted: August 1, 2016; Published: August 22, 2016

\begin{abstract}
The present study represents the efforts to determine whether exposing the language learners to an intralingually subtitled film can improve their listening comprehension or not. In order to find that out, an experiment in which two groups of five intermediate level students studying in Chabahar maritime university were exposed to a series of videos was designed. One group watched the videos with English subtitle and the other group without any subtitles. After using independent T-test the $\mathrm{p}$ value $(\mathrm{p}=.000<.05)$ shows that the ESG outperformed the WSG.
\end{abstract}

Keywords: Film, Subtitles, Listening Comprehension Ability

\section{Introduction}

We all may have seen some old movies in which some explanations about the movie were shown between the sequences; these explanations are called intertitles. Intertitles were mainly used for the silent movies. In 1927, with the invention of sound films, people could hear the actors, so there was no need for further explanations. Yet there were some comprehension problems for those who did not understand the language. Film producers could dub the films or they also could insert the translation or the explanation inside the picture; thus, they invented what now we know as subtitles. Nowadays, with ever-increasing role of technology in education systems all around the world, the question arises as if we can use intralingual subtitles as a means of improving listening comprehension of the language learners. Even though some studies have been conducted in the context of Iran, which have shown that the pre-intermediate language learners perform much better respectively with Persian and English subtitles (Hayati, 2011), that is not enough, and there is still a missing link between listening comprehension and subtitles. In order to fill this gap, the authors separated their students into two intermediate groups. During five sessions, one of these groups was shown films without any subtitles, and the other group was shown films with English subtitle. The objective of this study was to determine whether if there were any differences between the levels of comprehension between these two groups of students.

\section{Literature Review}

Subtitles are mostly known for their purpose of translating the oral dialogue of films or television programs into written text. This often involves viewers whose L1 is not the same as the language in the spoken dialogue and are given subtitles so that they can understand what is going on. This type of L1 subtitling is what we normally find in English speaking series and movies in Iran where people download Persian subtitles so that they can comprehend the scenes better. However, there are people who not only try to enjoy a movie but also at the same time try to learn another language, particularly English. Many educators also believe that television programs with captions seem to provide a rich context for foreign language acquisition. It is also argued that viewers are, generally, quite motivated to understand what is shown and said on television when captions are provided (Danan, 2004).

Markham (1989) investigated the effects of subtitled TV programs upon listening comprehension of beginner, intermediate and advanced learners of English. He used two 
subtitled videos on topics that the learners did not know about. Each group watched both movies with and without subtitles. He measured the participants' comprehension through multiple choice questions based on the language of the video. Coming to a point where all three groups using the subtitles performed significantly better, he speculated that ESL (English as a Second Language) students might be able to improve their listening and reading comprehension simultaneously.

Vander plank (1990) had also examined how learners of English used captions over a three-month period. Those who took notes while watching captioned videos produced more accurate language on subsequent comprehension exercises. Those who did not take notes comprehended as well as the note-taking group but did not retain specific language used in the videos. He concluded that attention and processing are important for the intake and long-term retention of forms through caption.

Garza (1991) compared Russian ESL learners' comprehension of video segments with second language subtitles to that of video segments without captions. Garza's data clearly showed that a textually enhanced visual channel, which presents information redundant to that presented by the auditory channel, facilitates students' comprehension.

In 1992 Danan (as cited in Hayati \& Mohmedy, 2011) investigated the effects of different subtitling conditions on vocabulary recall. She found that, as Holobow et al (1984) did, that reversed subtitling not only produced the most favorable results, but that bimodal input also positively increased vocabulary recollection. The results also showed that this method is beneficial for beginners using such bimodal input, which was not the case in the study conducted by Holobow et al. She explains the success of reversed subtitling for vocabulary recall through the way in which translation facilitates foreign language encoding and that it may help with the segmentation problems. She continues that students often have difficulty recognizing word boundaries in the spoken language, especially if they are not familiar with some of the words. Listening to and reading the text at the same time can at least help students distinguish known from unknown words.

Guillory (1998) found that subtitles are helpful for beginner learners. However, she found that beginner students would benefit more when only key words are presented as subtitles rather than having the entire sentences present on screen as subtitles. She noted that key-word subtitling might be better for beginning-level learners because it may not impose as large of a cognitive load.

In 1999 Koostra, Jonannes and Beentjeshad a research on 246 Dutch children in Grade 4 (before any formal instruction in English) and Grade 6 (following 1 year of English at school) after they watched a 15-minute American documentary shown twice with or without subtitles. The study demonstrated that children acquired more English vocabulary from watching subtitled television, although even children in the condition without subtitles learned some new words. Children in the subtitled condition also performed significantly better on a word recognition test, consisting of words heard in the soundtrack and words that could have been used in the context of the particular program.

Also in 2002 Bird and Williams focused on the implicit and explicit learning of spoken words and non-words. Implicit learning pertained to auditory word recognition while explicit learning referred to the intentional recollection and conscious retention of aural stimuli. A first experiment with 16 English native and 16 advanced non-native speakers demonstrated that participants in the captioned condition were better able to implicitly retain the phonological information they had just processed.

Mei-ling (2007) examined teaching English listening and speaking through films. The results suggest that English films pay a positive role in motivating students to learn English listening and speaking.

Also in 2011 Hayati and Mohmedi conducted a research in which a total of 200 intermediate students, 90 were picked based on a proficiency test. The students viewed only one of the three treatment conditions: English subtitles, Persian subtitles, no subtitles. After each viewing session, six sets of multiple-choice tests were administered to examine listening comprehension rates. The results revealed that the English subtitles group performed at a considerably higher level than the Persian subtitles group, which in turn performed at a substantially higher level than the no subtitle group on the listening test.

In most of these studies, the positive effects of subtitling on productive skills such as verbatim recall and retention, reuse of vocabulary in the proper context, as well as communicative performance in specific oral and written communication tasks has been demonstrated. Nevertheless, although the interest in subtitled materials is relatively growing, research in this field is still limited. In fact, the connection between the availability of subtitles and listening comprehension seems to be missing in the instructional setting and it needs to be examined by a systematic study. Consequently, the main goal of the present research is to determine whether captions and subtitles can also improve listening comprehension. More importantly, it is hoped to find out which one is likely to be more effective in developing listening comprehension: English subtitles with English dialogues or English dialogues with no subtitle.

\section{Methodology}

\subsection{Design}

The Design of this study is quasi-experimental in nature, and the data are gathered in a quantitative form. This method was chosen so that the researcher is allowed to control the assignment to the treatment condition, but using some criteria, other than random assignments as well.

\subsection{Participants}

All the participants of this study were the intermediate students of Chabahar maritime university. The number of 
subjects was 10, all of whom were selected via a proficiency test and equally divided into two groups. One group was exposed to films without subtitles and the other group was exposed to films with English subtitles. The participants were of the average age of 22 . The researchers themselves carried out the experiment in both the control group and the experimental group. This way the risk of making mistakes was lowered and everything was observed carefully.

\subsection{Instruments}

1. English Language Proficiency Test (Sharpe, 2001): The test contained 70 multiple choice items, and it was used to enable the researchers to select a homogeneous group. This test consisted of grammar (31 items), vocabulary (26 items) and reading comprehension (three passages with 13 items). The time allotted to answer the test was 60 minutes.

2. Comprehension test: Six sets of multiple-choice tests, with 10 items each, were derived from the video episodes (one for each video segment) to test the participants' comprehension. Each question contained language that occurred somewhere in the episode. A final comprehension test was also administered.

\subsection{Procedure}

The experiment, lasting for 5 sessions, was conducted at the language laboratory of Chabahar maritime university. The following three steps were taken in this study:

Step 1: A proficiency test was administered to about 40 students out of which only 10 were accepted as intermediate students. The allotted time for answering the questions was 60 minutes.

Step 2: Based on their score in language proficiency test, the participants were randomly assigned to two groups, that is, English Subtitle Group (ESG), and Without Subtitle Group (WSG).

Step 3: At this stage, the two groups were asked to watch one part of the episode on the same day, and in order to increase the reliability of the study, each group watched the same segment with the assigned condition, namely ESG or WSG. By the end of each session, immediately after watching the film, a multiple-choice comprehension test was administered in order to evaluate their listening comprehension and provide grounds for comparison.

Finally, an independent T-test was used to determine whether the differences between mean scores of ESG and WSG were statistically significant.

\section{Results}

Each participant was given 1 point for each correct answer, with the highest possible score being 10 and the lowest possible score being 0 . From the total average scores obtained by the groups, the mean of ESG condition was substantially higher than PSG condition. These results verified that students receiving the episode with English subtitle outperformed the other groups namely WSG.

Table 1. Shows the mean of each group after the final posttest: Final T-test variable 1.

\begin{tabular}{lllll}
\hline Group Statistics & groups & N & Mean & Std. Deviation \\
\hline ESG & 1.00 & 5 & 40.7000 & Std. Error Mean \\
WSG & 2.00 & 5 & 19.8400 & .48580 \\
\hline
\end{tabular}

\begin{tabular}{|c|c|c|c|c|c|c|c|c|c|c|}
\hline \multicolumn{11}{|c|}{ Independent Samples Test } \\
\hline & & \multicolumn{2}{|c|}{$\begin{array}{c}\text { Levene's Test for Equality of } \\
\text { Variances }\end{array}$} & \multicolumn{7}{|c|}{ t-test for Equality of Means } \\
\hline & & \multirow[b]{2}{*}{$\mathrm{F}$} & \multirow[b]{2}{*}{ Sig. } & \multirow[b]{2}{*}{$t$} & \multirow[b]{2}{*}{ df } & \multirow[b]{2}{*}{ Sig. (2-tailed) } & \multirow{2}{*}{$\begin{array}{c}\text { Mean } \\
\text { Difference }\end{array}$} & \multirow{2}{*}{$\begin{array}{l}\text { Std. Error } \\
\text { Difference }\end{array}$} & \multicolumn{2}{|c|}{$\begin{array}{l}\text { 95\% Confidence Interval of the } \\
\text { Difference }\end{array}$} \\
\hline & & & & & & & & & Lower & Upper \\
\hline ESG & $\begin{array}{l}\text { Equal variances } \\
\text { assumed }\end{array}$ & .035 & .855 & & 8 & .000 & 20.86000 & .65772 & 19.34329 & 22.37671 \\
\hline & $\begin{array}{l}\text { Equal variances not } \\
\text { assumed }\end{array}$ & & & 31.715 & 7.934 & .000 & 20.86000 & .65772 & 19.34109 & 22.37891 \\
\hline
\end{tabular}

Fig. 1. Independent sample test.

Table 1 shows the results of the mean for both groups. As it can be concluded from the table, the mean score of the ESG group is 40.7000 and the mean score for the WSG is 19.8400 .

Close consideration toward the mean difference of the two groups $(.000)$ and, of course, the $p$ value $(p=.000<.05)$ in figure 1 shows that the ESG outperformed the WSG. The above table shows the results in a more tangible manner.

To sum up the results of this study, the group with English subtitle (ESG) had a much higher score in the posttest compared to the group without any subtitles (WSG). The participants also mentioned that watching videos with subtitle helped them to remember words easier and to understand and comprehend the videos better. It should also be mentioned that the results showed that there are similarities in the outcomes of this study and Hayati' sresearch.

\section{Discussion}

Based on the results of the present study, intermediate students benefited this method and input because the proficiency level of intermediate students in terms of therange of vocabulary items and listening skill was high 
enough. Therefore, the intermediate students can understand the spoken language better and refer less to the subtitles except when they do not know the meaning of some key words, which are essential for comprehension. It is only then that they look at the key word to know the meaning; thus, there is no long translation process. To be exact, there is no need to switch from one language to another since it takes time, and the learners may lag behind and lose the track.

The results also indicate that subtitles in the English language helped student with a better listening comprehension and gave the students the opportunity to receive visual as wellas auditory messages. It seems that reading and listening messages instantaneously enhance learning of foreign language. Furthermore, most students mentioned that video subtitles in the target language did help them associate the auditory and written forms of words more easily and quickly than did videos without subtitles.

\section{Conclusion}

The purpose of this study was to investigate what kind of film is more effective in developing listening comprehension ability: ESG or WSG in the context of intermediate EFL students. Both groups were exposed to different treatments. ESG watched the movie with English subtitles and English soundtrack, and WSG watched the same film without subtitles but with the same soundtrack.

However the ESG reported a much higher understanding of the media they were exposed to, which showed that watching movies with subtitle can be much more effective for intermediate students who have a better understanding toward L2 and can use subtitles as means to look for key words if need be, and comprehend it better.

\section{References}

[1] Bird, S. \&. (2002). The effect of bimodal input on implicit and explicit memory: an investigation of within-language subtitling. Applied Psycholinguistics, 23, 4, 509-533.

[2] Danan, M. (1992). Reversed subtitling and dual coding theory: new direction for foreign language instruction. Language Learning, 42, 4, 497-527.

[3] Danan, M. (2004). Captioning and subtitling: Undervalued language learning strategies. Meta, 49, 67-77.

[4] Garza, T. (1991). Evaluating the use of captioned video materials in advanced foreign language learning. Foreign Language Annals, 24, 239-258.

[5] Guillory, H. (1998). The effects of key word captions to authentic French video in foreign language instruction. CALICO Journal, 15(1-3), 89-108.

[6] Hayati, A., \& Mohmedy, F. (2011). The effect of films with and without subtitles on listening. British Journal of Educational Technology.

[7] Koostra, C. M. (1999). Children's vocabulary acquisition in aforeign language through watching subtitled television programs at home. Educational Technology Research \& Development, 47, 1, 51-60.

[8] Markham, P. (1998). Theeffects of captioned television videotapesonthe listening comprehension of beginning, intermediate and advanced ESL students. Educational Technology, 29, 10, 38-41.

[9] Mei-ling, T. (2007). A study on the teaching English listening and speaking through films. Journal of Huaihua University, 11, 151-152.

[10] Vanderplank, R. (1990). Paying attention to the words: Practical and theoretical problems in watching television programmes with uni-lingual (CEEFAX) sub-titles. System, 18, 221-234. 